\title{
SENTENCIAS RECIENTES EN MATERIA TRIBUTARIA DE LAS CORTES DE APELACIONES Y DE LA CORTE SUPREMA: DICIEMBRE DE 2009
}

\author{
RECENT RULINGS ON TAX MATTERS FROM THE COURT OF \\ APPEALS AND THE SUPREME COURT: DECEMBER OF 2009
}

\section{PATRICIO MASBERNAT ${ }^{*}$}

\begin{abstract}
RESUMEN: EI presente estudio analiza un grupo de sentencias de las cortes de Apelaciones y Suprema, en materias vinculadas al Derecho Tributario. En ellas se puede observar las líneas jurisprudenciales, los votos de minoría, y las materias que normalmente se debaten en Chile. Este trabajo intenta hacer observaciones acerca de aspectos que las sentencias normalmente no tratan debiendo hacerlo, o que tratan de modo deficiente. Asimismo, el autor intenta mostrar las deficiencias argumentales de las sentencias en relación a las conclusiones obtenidas.
\end{abstract}

Palabras clave: decisiones judiciales, Derecho Tributario, recursos judiciales.

\begin{abstract}
This paper analyzes a group of judicial decisions from the Court of Appeals and the Supreme Court, in matters connected to Tax Law. In them, it is possible to observe the jurisprudential lines, the minority votes, and the matters that normally are debated in Chile. This work tries to make observations about aspects that the judgments normally do not mention, or that are treated poorly. Also, the author attempts to show deficiencies in the argumentation of the judgments for obtaining conclusions.
\end{abstract}

Key words: judgments, Tax Law, remedy for appeal, nullity.

En estas páginas, expondré acerca de un grupo de sentencias que recaen en litigios tributarios o aduaneros, dictadas recientemente por diversas Cortes de Apelaciones y la Corte Suprema. Esta metodología busca mostrar cuáles son las materias acerca de las cuales se litiga, su contenido, las líneas jurisprudenciales (si las hubiere) o los debates (contradicciones de criterios) entre las decisiones judiciales, etc. Finalizaré con algunas observaciones acerca de las sentencias expuestas ${ }^{1}$.

1. CASO "HINOJOSA BERTOLINE, CARLOS C/ SERVICIO DE IMPUESTOS INTERNOS", CORTE DE APELACIONES DE CONCEPCIÓN, SENTENCIA DE 1 DE DICIEMBRE DE 2009, AUTOS ROL 475-09. RECURSO DE APELACIÓN, RECHAZADO (PROCEDIMIENTO DE RECLAMACIÓN TRIBUTARIA). MATERIA: PRESCRIPCIÓN, ONUS PROBANDI, EFECTOS DE LA NULIDAD DE PROCEDIMIENTO SUSTANCIADO POR FUNCIONARIO

INCOMPETENTE O CON POTESTADES JURISDICCIONALES DELEGADAS

El contribuyente interpuso reclamación en contra de liquidaciones de 
impuestos efectuadas por el SII. Obteniendo fallo adverso, lo apela. Por los fundamentos explicitados más adelante, la Corte de Apelaciones rechaza el recurso y confirma la sentencia impugnada.

En su apelación, plantea que ha operado la prescripción de la obligación tributaria y su respectiva acción de cobro, por lo que debieran dejarse sin efecto las liquidaciones reclamadas correspondientes a períodos tributarios de 1999, 2000, 2002. La reclamación fue interpuesta en junio de 2003 y proveída primeramente por un juez delegado que no tenía facultades para ello, de manera que, sostiene, dicho acto nulo no pudo interrumpir la prescripción, lo que ocurrió cuando lo hizo el juez natural, el 4 de enero de 2008, fecha a la cual habían transcurridos los plazos de prescripción que se alegan.

Por su parte, el Fisco de Chile solicita el rechazo del recurso, sosteniendo que no es procedente esta alegación en esta instancia, ya que conforme a los arts. 123 y siguientes del CT en relación al art. 148 CT no resulta aplicable en el procedimiento de reclamación lo dispuesto en el 310 del CPC.

La Corte de Apelaciones decide, respecto de este punto, que la excepción de prescripción puede ser alegada en cualquier estado de la causa y en segunda instancia, antes de la vista de la causa, conforme a lo dispuesto en el art. 310 CPC, por aplicación supletoria, conforme a lo dispuesto en el art. 2 CT.

El apelante, asimismo, sostiene, que el SII no ha probado legalmente que las facturas objetadas sean falsas, que no ha tachado de "no fidedigna la contabilidad del contribuyente"; por lo que no procede rechazar el costo de las facturas cuestionadas para los efectos del IRPC y no cabe presumir ningún retiro para los efectos del IGC.

Respecto de los hechos, la Corte recuerda que el SII practicó las liquidaciones en abril de 2003, las que el contribuyente reclamó en junio de 2003; que por sentencia de septiembre de 2003 se rechazó el reclamo, el que fue apelado; resolviéndose la apelación en sentencia de diciembre de 2006, en que la Corte invalidó todo lo obrado en la causa por no haber sido conocida por el tribunal establecido en la ley, disponiéndose que debía la reclamación ser tramitada y resuelta por el funcionario que corresponde, anulándose todo lo obrado desde la providencia del reclamo.

Agrega que conforme al art. 24 inciso final CT, el término necesario para declarar la prescripción se suspende durante el período en que el SII se encuentre impedido de girar la totalidad o parte de los impuestos comprendidos en una liquidación, lo que ocurre cuando ha sido objeto de un reclamo por parte del contribuyente. Por ello, continúa razonando, la reclamación presentada suspendió el término de prescripción; estado que se mantiene hasta que se resuelva por sentencia ejecutoriada la presentación efectuada por el contribuyente en orden a que se deje sin efecto la liquidación practicada. La circunstancia de que se haya decretado la nulidad de todo lo obrado no obsta a dicha conclusión, porque es el reclamo presentado por el contribuyente el que tiene la virtud de suspender el curso de la prescripción, acto procesal que no quedó afectado por la declaración de nulidad, pues dicha resolución judicial dispuso que debía ser tramitada y resuelta por el funcionario competente.

Asimismo, recuerda que según el art. 200 CT existen dos plazos para 
computar la prescripción, uno que constituye la regla general de 3 años y otro excepcional de 6 años, contado desde que se hizo exigible el impuesto, siempre que este sea de aquellos sujetos a declaración y tal declaración no se hubiere presentado o si la presentada fuera maliciosamente falsa. En el caso sub lite, el SII concluyó que las declaraciones de la reclamante se hallaban en esta última situación, por haberse establecido en la revisión contable llevada a cabo que las facturas en cuestión son ideológicamente falsas.

Frente a ello, correspondía al contribuyente, de acuerdo al art. 21 CT, desvirtuar semejante imputación, acreditando que las operaciones de que daban cuenta los documentos cuestionados efectivamente se habían realizado, lo que no aconteció. Como lo ha indicado la Corte de Apelaciones de Concepción en otras ocasiones (autos rol 1884-2008) y conforme a lo resuelto por reiterada jurisprudencia de la Corte Suprema de Justicia, en materia tributaria la carga de la prueba corresponde en todos los casos al contribuyente, sin que el SIl tenga carga alguna en dicho sentido, ya que como ente fiscalizador de los contribuyentes no tiene la calidad de parte del procedimiento, limitándose su actuación a lo que le ordena la ley.

Estas apreciaciones, plantea el tribunal de alzada, se encuentran corroboradas por lo dispuesto en el DL № 825 LIVA en el art. 23 № 5 en su letra d) y, agrega en su C. 18을 lo que reproduzco a objeto de un posterior comentario:

$18^{\circ}$.- Que el Servicio de Impuestos Internos tiene la facultad que nace de la disposición de que se trata, de objetar no solo las facturas, pues ellas pueden corresponder a operaciones ficticias, de un monto distinto al consignado en ellas o a otras circunstancias que las hagan indignas de fe, sino también la efectividad de las operaciones mismas, pues ello aparece de un modo claro de la misma norma, sea de manera explícita, en el número 5 del artículo 23, inciso tercero letra d), como de un modo implícito cuando se objeta una factura por no fidedigna o falsa, pues ambas hipótesis pueden llevar envuelta la posibilidad de corresponder a operaciones no realizadas;

2. CASO "FISCO-TESORERÍA PROVINCIAL BIO-BIO C/ REYES Y REYES SOCIEDAD LTDA". CORTE DE APELACIONES DE CONCEPCIÓN, SENTENCIA DE 11 DE DICIEMBRE DE 2009, AUTOS ROL 932-09. RECURSO DE APELACIÓN EN SENTENCIA DE PROCEDIMIENTO DE RECLAMACIÓN (ACOGIDO). MATERIA:

EXCEPCIÓN DE PRESCRIPCIÓN, DESECHADA

El SII efectuó liquidación de impuestos a un contribuyente, quien reclamó de dicho acto (el 5 de noviembre de 1996), petición que fue desestimada por el juez tributario (el 14 de enero de 1997). Con ello, el SII nuevamente giró impuestos. Dichos giros fueron anulados el 13 de julio de 2006, por haberse anulado a su vez el fallo del Tribunal Tributario pronunciado por un funcionario delegado actuando como Juez Tributario. Posteriormente, se volvió a dictar sentencia del mismo reclamo con fecha 
10 de diciembre de 2007, precediéndose al giro con fecha 8 de marzo de 2008. En el procedimiento de cobro, el contribuyente alegó que los impuestos se encontraban prescritos, lo que se acoge en resolución de 30 de abril de 2009, que es objeto de un recurso de apelación. El contribuyente intenta evitar el pago de los tributos amparándose en la excepción de prescripción.

En su favor, este último alega que el reclamo presentado y proveído en su oportunidad por el Tribunal Tributario no tiene el mérito de suspender el plazo de prescripción por cuanto esa presentación, planteada a un funcionario que no es Juez, no puede tener la virtud de suspender la prescripción, pues para ello se requiere que cumpla los requisitos de forma y fondo de un reclamo, lo que solo se verifica con la providencia recaída en él.

Adiciona que, conforme al art. 125 CT, en caso de no cumplirse con los requisitos legales, el Director Regional puede ordenar que se subsane bajo apercibimiento de tenerse por no presentada y, por lo mismo, no puede entenderse suspendido el plazo de prescripción. De ahí que algunos autores sostengan que "solo existe válida interposición del reclamo cuando aquel se tiene por interpuesto válidamente por el Juez correspondiente, puesto que antes de aquello el reclamo puede tenerse por no interpuesto, por ejemplo por estar fuera de plazo o no estar firmado o por no cumplir con los requisitos" legales ${ }^{2}$.

Frente al alegato del contribuyente en orden a que se declaren prescritas sus deudas tributarias reclamadas, la Corte sostiene que debe analizar si el plazo de prescripción a que se refiere el art. 201 CT inciso final estuvo efectivamente suspendido, es decir, si el SIl estuvo impedido, de acuerdo a lo dispuesto en el inciso $2^{\circ}$ del art. 24 CT, de girar la totalidad o parte de los impuestos comprendidos en una liquidación cuyas partidas o elementos hayan sido objeto de una reclamación tributaria. Conforme con dicha norma (que se reproduce igual que en el fallo de primera instancia) una vez deducida la reclamación, no es posible girar los impuestos (y multas, en su caso) hasta que dicho proceso finalice.

La Corte expone que consta en el proceso el reclamo de las liquidación interpuesto por el contribuyente el 5 de noviembre de 1996, desestimado el 14 de enero de 1997, con lo que se procedió a girar los impuestos, giros que quedaron sin efectos el 13 de julio de 2006 por haberse anulado a su vez el fallo de 1997 debido a que fue emitido por funcionario incompetente. Posteriormente, se volvió a dictar sentencia con fecha 10 de diciembre de 2007, procediéndose al giro con fecha 8 de marzo de 2008.

Para la Corte, el aspecto esencial de este asunto (la prescripción) está en determinar si el reclamo deducido por el contribuyente tuvo la virtud de suspender o no la acción del Fisco para perseguir el pago del impuesto, atendido que el procedimiento incoado a partir de dicho reclamo fue anulado, al igual que los giros originados en el rechazo de la reclamación planteada, decidida por quien carecía de facultades legales para ello. El impedimento para que el Sll gire los impuestos se produce cuando el contribuyente "hubiere deducido reclamación", cosa que en la especie ocurrió.

El tribunal de alzada plantea que el reclamo del contribuyente es fruto 
del ejercicio de un derecho legal, que no tiene naturaleza de acto administrativo, no es una decisión de la Administración y, por ello, no se ha visto alcanzado por la declaración de nulidad del procedimiento. Tanto es así, agrega, que al anularse el proceso se volvió a tramitar el mismo reclamo, fallándose el 10 de diciembre de 2007, sentencia que dejó nuevamente abierta la posibilidad del SII de girar los impuestos y multas, lo que hizo el 8 de marzo de 2008.

El sentenciador estima incorrecto el análisis del contribuyente en relación al art. $24 \mathrm{CT}$, ya que este es claro en cuanto a que para suspenderse la prescripción solo se requiere que el contribuyente "haya deducido reclamación", por lo cual la suspensión ha de contarse desde la fecha en que esa reclamación se deduzca y no desde la fecha en que fuere proveída. Distinto es que posteriormente, por motivos legales, dicha reclamación se tenga por no interpuesta, pues en tal caso, se entiende que nunca hubo reclamo legal. Y esto no ha sucedido en esta causa.

Agrega, en el C. 7, que el reclamo presentado de buena fe ante quien no tenía facultades para resolverlo no pierde el carácter de tal ni puede dejar de producir el efecto de suspensión de la prescripción desde que la autoridad administrativa, a raíz del referido reclamo estuvo imposibilitada de girar los impuestos, al punto que los giros efectuados después de rechazarse por el Juez Tributario la reclamación, debieron ser dejados sin efecto. En definitiva, lo que inhibe al SIl de girar los impuestos es la interposición del reclamo y no su providencia, de modo que basta con el reclamo para que se suspenda el plazo de prescripción de acuerdo a las normas legales.

Por ello, resolver este asunto de otra forma atentaría contra la equidad.

\section{CASO "FISCO-TESORERÍA PROVINCIAL BIO BIO C/ REYES} ARANGUEZ, RENATO". CORTE DE APELACIONES DE CONCEPCIÓN, SENTENCIA DE 11 DE DICIEMBRE DE 2009, AUTOS ROL 931-09. RECURSO DE APELACIÓN (PROCEDIMIENTO DE RECLAMACIÓN TRIBUTARIA). RECURSO DE APELACIÓN EN SENTENCIA DE PROCEDIMIENTO DE RECLAMACIÓN (ACOGIDO). MATERIA: EXCEPCIÓN DE PRESCRIPCIÓN, DESECHADA

Este caso es enteramente semejante al anterior: el actor presenta las mismas pretensiones y el Tribunal resuelve del mismo modo y con los mismos fundamentos judiciales (solo cambia el contribuyente, que además se encuentra vinculado con el anterior).

El contribuyente reclamó la liquidación de impuestos (26 de marzo de 1997), petición que fue desestimada por el Juez Tributario (6 de octubre de 1997), procediendo el SII a girar los impuestos, giro que fue anulado (13 de julio de 2006) por haberse anulado a su vez el fallo del Tribunal Tributario pronunciado por el Juez Tributario sobre la base de que el funcionario competente era el Director Regional del SIl y no quien actuaba delegado por este, sustanciando indebidamente el proceso. Posteriormente, se volvió a dictar sentencia (8 de abril de 2008) y se giraron nuevamente los impuestos (22 de abril de 2008). En el procedimiento de cobro, se 
declararon prescritos los tributos (resolución de 30 de abril de 2009).

En el procedimiento de la apelación, acogida en definitiva, el contribuyente solicitó que se declarara extinguida la deuda tributaria por los mismos fundamentos del caso anterior, pues los hechos son análogos, lo que el tribunal rechazó por exactamente las mismas razones.

4. CASO "INMOBILIARIA E INVERSIONES DON VÍCTOR Y COMPAÑÍA LTDA. C/ SERVICIO DE IMPUESTOS INTERNOS". CORTE SUPREMA, SENTENCIA DE 29 DE DICIEMBRE DE 2009, AUTOS ROL 2531-08. RECURSO DE CASACIÓN EN EL FONDO, ACOGIDO (RECLAMACIÓN TRIBUTARIA). MATERIA: PRESCRIPCIÓN TRIBUTARIA, COBRO DE TRIBUTOS, COMPETENCIA DEL SII

En este litigio, la contribuyente, dedujo recurso de casación en el fondo contra la sentencia de la Corte de Apelaciones que revocó la de primera instancia que había acogido la demanda interpuesta y declarado prescrita una deuda tributaria, con sus reajustes, intereses, multas y demás recargos, decidiendo en su lugar, rechazar la prescripción extintiva de la acción de cobro de tributos alegada.

El recurso se fundamenta en una supuesta infracción de los arts. 200 y 201 CT, reguladores de la prescripción extintiva, ya que entre el vencimiento del pago del impuesto y el requerimiento judicial para su pago transcurrieron más de tres años.

La Corte Suprema expone los hechos de este modo: el plazo legal en que debió efectuarse el pago del tributo IVA, cuyo cobro perseguía el Servicio de Tesorería, concluyó el 12 de septiembre de 1997; el SII no ha denunciado que no se hubiere presentado la declaración de impuestos o la presentada fuere maliciosamente falsa; la demandante fue notificada y requerida de pago el día 8 de noviembre del año 2000. Por tanto, a la fecha en que la contribuyente morosa fue notificada y requerida judicialmente de pago en la causa ejecutiva de cobro de impuestos, había transcurrido el plazo de tres años, plazo aplicable en la especie, necesario para la prescripción extintiva de la acción ejercida. Al no entenderlo así, los jueces del fondo transgredieron las normas legales respectivas.

\section{CASO "LAZCANO MALDONADO, MANUEL A. C/ SERVICIOS DE} IMPUESTOS INTERNOS", CORTE DE APELACIONES DE

SANTIAGO, SENTENCIA DE 24 DE DICIEMBRE DE 2009, AUTOS ROL 3713-09, CASACIÓN DE OFICIO, POR MAYORÍA (VOTO

DISIDENTE). MATERIA: NULIDAD DE DERECHO PÚBLICO DE LA SENTENCIA PRONUNCIADA POR FUNCIONARIO NO COMPETENTE (FUNCIONARIO CON FACULTADES JURISDICCIONALES DELEGADAS)

La causa comenzó con un reclamo contra una liquidación del SII presentado ante el juez tributario. Dicho asunto fue tramitado por un funcionario con facultades delegadas, mediante resolución exenta, por parte del Director Regional del SII. 
La Corte revoca de oficio el proceso, por fundamentos en general conocidos, los que no por ello son importantes de mencionar, sobre todo para hacer contrapunto del voto disidente el cual revela otra perspectiva válida de este problema.

La sentencia recuerda que la potestad para resolver estas reclamaciones se ha otorgado al Director Regional del SII, por el art. artículo $115 \mathrm{CT}$. Esta competencia sería propiamente jurisdiccional y no se trataría del agotamiento de la vía administrativa previa a recurrir a los tribunales, lo que se deriva de la naturaleza y el contenido de la actividad jurisdiccional (poder que tiene el Estado para resolver los conflictos jurídicos particulares, mediante la aplicación de las normas objetivas que este, por medio de sus órganos, estima pertinente disponer).

Agrega que normas del CT y la LOSII autorizan a los directores regionales del Servicio a delegar dichas funciones, lo cual se contrapone con diversos principios constitucionales.

La función jurisdiccional debe observar los principios constitucionales respectivos, especialmente, los de legalidad, imparcialidad e independencia del órgano que conoce del juicio.

Asimismo, reconoce una serie principios en el orden tributario, que determinan que el Estado debe ejercer la potestad tributaria, tanto al imponer tributos como al fiscalizarlos y resolver las controversias que puedan presentarse, conforme al de legalidad, no discriminación arbitraria, bien común, y del debido proceso.

El debido proceso exige el establecimiento de los tribunales en forma permanente por el legislador y con anterioridad a la iniciación del juicio, el que deberá ser seguido ante un juez imparcial, dentro de un procedimiento contradictorio, bilateral y con igualdad de derechos para las partes, que permita exponer adecuadamente las pretensiones, defensas y oposiciones, en su caso, haciendo posible el ofrecimiento, aceptación y recepción de los medios de prueba en que aquellas se fundan, obteniendo una decisión por un juzgador imparcial e independiente.

La sentencia recuerda que conforme al antiguo art. 116 del CT, el Director Nacional del SII, autorizó a los Directores Regionales para delegar algunas de sus atribuciones, reglamentando esta facultad, a funcionarios del Servicio, subordinados a ellos. Dicha norma legal fue declarada inconstitucional por sentencia del Tribunal Constitucional, publicada el DO el 29 de marzo de 2007, considerándoselo derogado conforme a la Constitución.

De ahí, la Corte deduce que el proceso a que se encuentra abocada se ha substanciado por autoridades administrativas que carecen de jurisdicción; vicio que influye substancialmente en su marcha y en lo dispositivo de su sentencia, por lo que decide invalidar la sentencia apelada y reponer la causa al estado que el Juez competente dé el debido trámite a la nulidad y reclamación interpuestas en estos autos, invalidándose consecuentemente todo lo obrado y, por consiguiente, omitiendo pronunciamiento respecto del recurso de apelación deducido en autos.

Por su parte, el voto disidente estima que no procede la invalidación de la sentencia, ya que las facultades desempeñadas por el funcionario que tramitó el reclamo, son de carácter administrativo y no jurisdiccional. 
La naturaleza del asunto sometido a la decisión del SII, añade, no cumple con los requisitos básicos de una contienda judicial, pues no existen dos partes en litigio, ni un tercero imparcial llamado a resolver la contienda, al contrario, se trata de un recurso jerárquico, presentado ante la autoridad administrativa que dictaminó sobre una determinada situación tributaria que afecta a un contribuyente, el que es resuelto conforme a los principios y reglas básicas de cualquier reclamo administrativo.

Le resulta demostrativo de que no existe el ejercicio de una facultad jurisdiccional, el hecho de que si el SII no se pronuncia sobre el reclamo dentro de un plazo de tres meses, se podrá pedir que este se tenga por rechazado (art. $135 \mathrm{CT}$ ), para los efectos de poder apelar para ante la Corte de Apelaciones. Ello es propio de los procedimientos administrativos, v.g., Ia LOC de Municipalidades, art. 140 letra c).

Sostiene que lo anterior no se condice con la forma en que puede terminar una contienda judicial, en que la sentencia definitiva solo puede ser reemplazada por los equivalentes jurisdiccionales que señala la ley, mas no por el valor que se le pueda dar al silencio del juez que conoce el asunto, quien siempre está obligado a tramitar y resolver sin que pueda excusarse de ejercer su autoridad, ni aún a falta de ley que resuelva la contienda sometida a su decisión (art. 10 COT).

Tampoco es obstáculo la denominación que las propias normas tributarias le otorguen a este tipo de procedimiento y a las facultades administrativas que ejerce el funcionario del Servicio que conoce y resuelve una reclamación de un contribuyente (tales como "juez", fallo", "instancia"), las que, en principio, pueden inducir a error.

\section{CASO "SORIA QUIROGA, JORGE C/ SERVICIO DE IMPUESTOS} INTERNOS". CORTE SUPREMA, SENTENCIA DE 15 DE DICIEMBRE

DE 2009, AUTOS ROL 1373-08, RECURSO DE CASACIÓN EN EL FONDO, DESESTIMADO (PROCEDIMIENTO DE RECLAMACIÓN). MATERIA: LIQUIDACIONES DEL IMPUESTO GLOBAL COMPLEMENTARIO, JUSTIFICACIÓN DE GASTOS

El contribuyente dedujo recurso de casación en contra de sentencia de alzada confirmatoria del fallo de primera instancia que hizo lugar en parte al reclamo en contra de liquidaciones de impuestos efectuadas por el SII, ordenando modificarlas.

El reclamo trae causa en la liquidación de diferencias de IGC del año tributario 2000, derivadas de que el SII estimó no justificados el origen y la disponibilidad de fondos destinados a financiar inversiones efectuadas en el año comercial 1999.

El contribuyente expone, en su recurso de apelación, que la liquidación se funda en que él no acreditó los fondos con que financió el $50 \%$ de la parte del precio de adquisición de un bien raíz, pagado al contado, sin que exista un elemento que lleve a establecer que la cuota de cada comprador sea tal porcentaje. Erróneamente, sostiene, la sentencia vincula la adquisición por partes iguales del bien raíz con el pago del precio de la casa, determinando que este se hace en la misma proporción en que se adquiere el inmueble, pese a que tal situación no aparece 
mencionada en la escritura. Expone que, conforme al art. $21 \mathrm{CT}$, el SIl no puede prescindir de las declaraciones de los contribuyentes. Establecer los porcentajes del modo expuesto constituye la aplicación de una presunción judicial que no atiende a ningún hecho establecido por los medios de prueba legales.

Asimismo, la sentencia recurrida viola las normas reguladoras de la prueba, al omitir ponderar y calificar el mérito de la totalidad de la prueba rendida por su parte, pues no se pronuncia sobre una serie de documentos que avalan los ingresos obtenidos por concepto de remuneraciones con los que se acredita el origen de los fondos con que pagó parte importante del precio contado de la casa.

Asimismo, infringe el art. 70 LIR y los arts. 19 y 20 CC, porque el tribunal aplica una exigencia adicional, como lo es la disponibilidad conforme a los criterios del Director Nacional del SIl que, interpretando tal disposición, en el oficio circular $\mathrm{N}$ o 8, establece una presunción administrativa, creando una exigencia adicional por vía administrativa que ha sido repudiada por los tribunales superiores de justicia. Además se infringen las normas señalados al limitar el plazo a que se atiende para considerar los flujos de ingresos y gastos a un año cronológico antes de la inversión. Ello importa una restricción al ahorro. Se trata de un límite no establecido en la ley.

Finalmente, denuncia la infracción del art. 70 inciso 1 LIR y art. 21 CT, al dar fuerza probatoria al informe del fiscalizador sobre gastos de vida del contribuyente, el que consiste en una hoja de trabajo que expresa por cada período mensual las estimaciones de ingresos y desembolsos, el que carece de antecedentes fundantes de referencia y se construye con supuestos subjetivos. Se trata de una estimación discrecional. Los gastos de vida del contribuyente deben probarse por el SIl de acuerdo al inciso $1^{\circ}$ del art. 70 CT. Por su parte, el art 21 CT obliga al Servicio a atenerse a las probanzas del contribuyente.

En su análisis, la Corte Suprema pone de relieve que el art. 21 CT no significa que el tribunal deba aceptar el mérito probatorio que de ellos pretenda el propio contribuyente y las conclusiones que este pueda extraer de tales probanzas, pues la obligación consiste en tomarlos en consideración por el tribunal, y su apreciación es una función jurisdiccional. De aceptarse el planteamiento del recurrente, se llegaría a la situación de que la labor de apreciación de las pruebas se trasladaría al contribuyente, lo que es inaceptable.

En cuanto a la infracción de normas reguladoras de la prueba denunciada, agrega que según reiteradamente ha resuelto la Corte Suprema, ellas se entienden vulneradas cuando los sentenciadores invierten la carga de la prueba, rechazan las pruebas que la ley admite, aceptan las que la ley rechaza, desconocen el valor probatorio de las que se produjeron en el proceso cuando la ley le asigna uno determinado de carácter obligatorio o alteran el orden de precedencia que la ley les diere. Lejos de ello, los reproches formulados en el recurso se relacionan únicamente con la forma como los jueces del fondo analizaron las probanzas rendidas en el proceso para establecer los hechos, arribaron a las conclusiones que expresaron y, a partir de ello, resolvieron lo que estimaron pertinente. Es decir, se trata de un problema de apreciación de 
la prueba, labor que corresponde a los jueces del fondo y que no puede ser variada por el tribunal de casación, a menos que se hayan vulnerado normas que en sí mismas determinen o tasen el valor concreto de un medio probatorio, estableciendo un parámetro fijo para ello, lo que en el presente caso no ha ocurrido.

Por su parte, el art. 70 LIR instituye una presunción simplemente legal, y exige al contribuyente probar el origen de los fondos con que ha efectuado sus gastos, desembolsos o inversiones, y de no hacerlo se presumirá que corresponden a utilidades afectas al IRPC O IRSC, atendiendo a la actividad principal del contribuyente. En las sentencias de primera y segunda instancia, se estableció que el contribuyente no acreditó que con los ingresos que obtuvo por concepto de sueldos entre los años 1994 y 1999 solventó el desembolso en cuestión, hecho que resulta inamovible para el tribunal de casación, que no puede variarlo porque su labor se limita a verificar la legalidad de un fallo en cuanto la ley ha sido aplicada a hechos determinados por los jueces del fondo. En sede de casación no pueden modificarse los hechos fijados por los jueces del fondo en uso de sus atribuciones legales, a menos que se haya denunciado y probado la infracción de normas reguladoras de la prueba, lo que en este caso no ha sucedido.

7. CASO "CANNOBIO HEMMELMANN, LILIANA C/ SERVICIO DE IMPUESTOS INTERNOS", CORTE DE APELACIONES DE CONCEPCIÓN, SENTENCIA DE 21 DE DICIEMBRE DE 2009, AUTOS ROL 59-09. RECURSO DE APELACIÓN, RECHAZADA

(RECLAMACIÓN TRIBUTARIA). MATERIA: PRESCRIPCIÓN, CARGA DE LA PRUEBA

Esta sentencia contiene semejantes fundamentos del caso №1, ya expuesto. Confirma la sentencia que rechazó la excepción de prescripción deducida, sobre la base que la prescripción se suspende durante el período en que el SII se encuentre impedido de girar la totalidad o parte de los impuestos comprendidos en una liquidación, lo que ocurre, cuando ha sido objeto de un reclamo por parte del contribuyente. La reclamación objeto de esta causa, agrega la Corte, tuvo la virtud de suspender el término de prescripción; estado que se mantiene hasta que se resuelva por sentencia ejecutoriada la presentación efectuada por el contribuyente en orden a que se deje sin efecto la liquidación practicada.

Asimismo, habiendo atribuido el SIl la condición de maliciosamente falsas a las declaraciones de la sociedad reclamante, por haber constatado, con ocasión de examinar sus antecedentes contables, que procedían de documentación irregular, corresponde al contribuyente, de acuerdo con el art. 21 CT, desvirtuar semejante imputación, acreditando que las operaciones de que daban cuenta los documentos cuestionados efectivamente se habían realizado, lo que no aconteció, lo que lleva al rechazo del recurso de apelación intentado. Agrega que el SII tiene la facultad de objetar tanto las facturas como también la efectividad de las operaciones, pues, ello aparece de un modo claro de la misma norma, sea de manera explícita, en el № 5 del art. 23, inciso 3 letra d) del DL 825 , 
como de un modo implícito cuando se objeta una factura por no fidedigna o falsa.

8. CORTE SUPREMA, SENTENCIA DE 22 DE DICIEMBRE DE 2009, AUTOS ROL 185-08. "PEDRO MORAL FERNÁNDEZ LTDA. C/ SERVICIO DE IMPUESTOS INTERNOS". PROCEDIMIENTO: RECURSO DE CASACIÓN EN EL FONDO, ACOGIDO (RECLAMACIÓN TRIBUTARIA). MATERIA: EXCEPCIÓN DE PRESCRIPCIÓN

El juez tributario, y la sentencia de la Corte de Apelaciones (confirmatoria), no hacen lugar al reclamo presentado por el contribuyente, confirmando el acta de denuncia y aplicándole una multa reducida al $100 \%$ de lo defraudado (en procedimiento de aplicación de multas, no procedimiento penal), porque en la investigación administrativa practicada por el SII, se detectó que había presentado en el Formulario 29, declaraciones maliciosamente falsas, invocando créditos fiscales inexistentes, fundados en el registro de facturas falsas emitidas por proveedores irregulares.

Presentada la excepción de prescripción por el contribuyente, esta fue desechada al determinarse que debe transcurrir un plazo de seis años, fundándose en el inciso $3^{\circ}$ del art. 200 CT. El acta de denuncia fue notificada el 24 de marzo de 2000, por los períodos tributarios comprendidos entre diciembre de 1995 y diciembre de 1998.

El recurso de casación denuncia que la sentencia no dio aplicación al art. 2 CT que ordena aplicar las normas de derecho común y a los arts. 94 y 95 del CP contienen el derecho común aplicable a la materia debatida. Dichas normas disponen que, en el caso de faltas, la acción prescribe en seis meses desde el día de la comisión del hecho respectivo, por lo que todas las infracciones cometidas antes del 30 de julio de 1997 -cual es la fecha de publicación de la ley № 19.506, la que agrega el inciso final del art. $200 \mathrm{CT}$, por lo que no sería aplicable por ser posterior a la comisión de los hechos- deben declararse prescritas a la época de la notificación del acta denuncia, i.e., el 24 de marzo de 2000. De aplicarse correctamente las normas citadas, se habría rebajado el monto de las multas.

La Corte Suprema, en su resolución, sostiene que la materia a que se refiere este proceso ha sido resuelta reiteradamente por ella acogiéndose de modo invariable planteamientos similares al del contribuyente de autos pues, efectivamente, en la época en que parte de los hechos ocurrieron no existía disposición legal especial expresa que reglara esta materia en el CT, escenario que cambió con la Ley №19.506 (D.O. 30 de julio de 1997), que modificó el art. 200 CT, entre otros, al que se agregó el inciso final, que fija un plazo de prescripción de 3 años (contados desde la fecha en que se cometió la infracción) a las acciones que tengan por objeto perseguir las sanciones de carácter pecuniario y otras que no accedan al pago de un impuesto. Por ello, antes de la dictación de esta ley, no existía norma expresa que reglara el plazo de prescripción de estas acciones, debiendo aplicarse supletoriamente las normas del derecho común.

El procedimiento que ha tenido lugar en este caso es el de aplicación 
de multas, i.e., un procedimiento infraccional que persigue la sanción de una mera falta, por lo que corresponde dar esa calificación y no la de delitos a los ilícitos objeto de esta causa. Por tanto, se trataba de hacer efectiva la responsabilidad infraccional del contribuyente por hechos acaecidos antes de la dictación de la Ley №19.506, de modo que el derecho común aplicable es el CP, específicamente, su art. 94, en cuanto dispone que la acción de las faltas prescribe en seis meses y su art. 95, que determina que ese tiempo se cuenta desde el día de la comisión del hecho respectivo.

En consecuencia, la sentencia ha incurrido en error de derecho, al aplicar equivocadamente en el caso de hechos anteriores al 30 de julio de 1997 el plazo del art. 200 del CT y no, como correspondía hacerlo, las disposiciones contenidas en los arts. 94 y 95 del CP, pues dichos hechos se perpetraron en 1996 y 1997, antes de la vigencia de la Ley №19.506 y tres y cuatro años antes de efectuarse la denuncia, fechada el 24 de marzo de 2000, por lo que el recurso de casación debe acogerse en la parte pertinente.

Respecto de las facturas fechadas posteriormente al 30 de julio de 1997, el Sll deberá, en su oportunidad, efectuar una nueva determinación de la multa impuesta, considerando lo resuelto precedentemente.

Este fallo tiene un voto disidente (Ministra Sra. Araneda), que no comparte esta decisión al ser de la opinión de rechazar el recurso de casación y confirmar íntegramente el fallo en virtud de que en los casos en que la infracción pudiere ser sancionada con multa y pena corporal, la facultad discrecional del Director del SII que contempla el inciso $3^{\circ}$ del art. 162 CT, de optar por el envío de los antecedentes al Director Regional para que aplique la multa que correspondiere a través del procedimiento administrativo, debe hacerse dentro de los plazos de prescripción, plazos en los cuales el Servicio podrá examinar y revisar las declaraciones presentadas por los contribuyentes. Los plazos de prescripción están indicados en el art. $200 \mathrm{CT}$, incisos $1^{\circ}$ y $2^{\circ}$.

Este caso recae en una declaración del contribuyente que ha sido formulada en forma maliciosamente falsa, por lo que el plazo que la ley le otorga al SII para examinar y revisar las declaraciones presentadas es de seis años, plazo dentro del cual el Director puede determinar la remisión de los antecedentes al Director Regional para la aplicación de la multa correspondiente, sin iniciar la acción penal. Es en este plazo que se extingue la acción del Servicio para perseguir las acciones pecuniarias que acceden a los impuestos adeudados. La decisión del SII de no instar por la investigación de delitos tributarios en sede penal, optando por iniciar un procedimiento de reclamación administrativa, no transforma la naturaleza jurídica del hecho ilícito. Esto se deriva, asimismo, del inciso $4^{\circ}$ del art. 162 CT, que permite deducir acción penal luego de iniciarse procedimiento administrativo. Por tanto, no podría sostenerse que al perseguir la sanción pecuniaria estaba conociendo de una falta y que, en forma posterior, por haber deducido denuncia o querella se "transformó" en delito, puesto que un hecho no puede constituir falta y delito a la vez. Asimismo, la existencia de una multa no transforma al hecho en falta, ya que ella es común a crímenes, delitos y faltas.

Tampoco nos encontramos en un caso de laguna legal que deba 
integrarse por aplicación de normas de derecho común. Es simplista y literalista aquella afirmación que dice que antes de la modificación introducida por la Ley 19.506 no existía plazo para ejercer la potestad sancionatoria administrativa, debiéndose integrar dicha laguna con el plazo de seis meses establecido para las faltas en el CP. Además, es inadmisible pues lleva al absurdo de que el Director del SIl solo podría ejercer su potestad sancionatoria dentro del plazo de seis meses, pudiendo, una vez transcurrido aquel, solo "interponer la respectiva denuncia o querella" en sede penal, lo cual es manifiestamente contrario a lo dispuesto en el art. 162 CT, cuyo sentido es que el Director del SIl puede ejercer su facultad discrecional de instar para que se aplique solo la multa que correspondiere en el respectivo procedimiento administrativo, dentro del plazo que tiene para revisar los impuestos sujetos a declaración ya que es innegable que la principal herramienta de fiscalización que posee el Servicio es el de revisar las liquidaciones y su documentación de respaldo, y ello se ejerce dentro de los períodos señalados en el citado art. 200 CT. Por tanto, es lógico que el sentido de la ley consiste en que dentro de ese período pueda ejercer su potestad sancionatoria e instar la sanción pecuniaria que determine, o procurar la investigación y sanción corporal y pecuniaria del delito tributario que detecte.

\section{CASO "CONTRA GONZÁLEZ URIARTE, EMILIO". CORTE} SUPREMA, SENTENCIA DE 2 DE DICIEMBRE DE 2009, AUTOS ROL 7640-08. RECURSO DE CASACIÓN EN EL FONDO (SII, RECHAZADO). MATERIA: FRAUDE TRIBUTARIO. APLICACIÓN DE LEY PENAL EN EL TIEMPO

En sentencia dictada por el Sexto Juzgado del Crimen de Santiago, autos rol $N^{\circ} 28.879$, de trece de junio de 2007, se absolvió al acusado Sr. Schaarmann del cargo de ser autor del delito contenido en el art. $97 \mathrm{~N}^{\circ} 4$ incisos $1^{\circ}$ y $2^{\circ}$ del CT, y se condena al Sr. González Uriarte, por su participación en calidad de autor del delito previsto en el art. $97 \mathrm{~N}^{\circ} 4$ inciso $1 \stackrel{0}{ }$ del CT.

En contra de esta última resolución, el SIl dedujo recurso de apelación. La Corte de Apelaciones de Santiago revocó la sentencia en la parte que condena al Sr. González Uriarte, absolviéndolo por estimar que no se cumplía a su respecto un requisito que exigiría el tipo penal respectivo, cual es el de tener la calidad de contribuyente.

En contra de la anterior decisión, el SIl dedujo recurso de casación en el fondo, fundado en que la Corte de Apelaciones califica como lícito un hecho que la ley tipifica como delito. Argumenta que la figura penal que debió ser aplicada por el tribunal era la contenida en el inciso $2^{\circ}$ del №4 del art. 97 del CT, y la circunstancia de no ser contribuyente el Sr. González no lo exime de estar obligado por las normas tributarias, como se deduce de un análisis sistemático del CT y del CP. EI SII agrega que resulta plenamente aplicable la comunicabilidad de la calidad personal del agente a todos los demás partícipes del delito, quienes deberán responder por su comisión, ya que se trata de un delito especial propio, como lo ha sostenido la Corte Suprema en otras sentencias. 
Finalmente, sostiene que es un error cometido en la sentencia de alzada sostener que la conducta que se reprocha al Sr. González Uriarte se incorporó recién como delictiva a partir de la dictación de la Ley № 19.738, publicada en el DO el 19 de junio de 2001, esto es, con posterioridad a los hechos investigados, que son de junio y noviembre de 1999.

Esta causa plantea cierta complejidad en sus hechos, que merecen una relación de cierta extensión.

Ciertos sujetos ingresaron facturas falsas de TRANSMETAL Ltda. en la contabilidad de la contribuyente SACYR S.A., los que esta última pagó y contabilizó, y determinó que declarara un IVA crédito fiscal superior al que efectivamente correspondía, pagando un tributo IVA inferior al que correspondía pagar, y, consecuencialmente, en el período correspondiente, un impuesto a la Renta inferior al que correspondía, por gastos rechazados, tributos que, finalmente, SACYR pagó al SIl como impuestos adeudados.

Se dedujeron cargos respecto del Sr. González Uriarte en calidad de autor del delito de fraude tributario previsto en el art. 97 № 4, inciso 1 CT. EI SII posteriormente dedujo acusación particular calidad de coautores de los tipos delictuales establecidos en el art. 97 № 4 inciso 1 y 2 CT.

La Corte de Apelaciones de Santiago, en su sentencia indicó que el hecho punible establecido en la causa no dice relación con el contribuyente, sino que con el tercero que dolosamente emplee procedimientos para desfigurar el verdadero monto de las operaciones realizadas, dejando vigente la discusión sobre la eventual aplicación del inciso $1^{\circ}$ del número $4^{\circ}$ del art. 97 CT. A continuación, dicha Corte comparó la realidad fáctica establecida con el tipo penal indicado, concluyendo que en esa descripción se supone que el agente del tipo penal es la persona del contribuyente afecto a la carga tributaria, por lo que no corresponde extender la responsabilidad penal a aquellos terceros que hubieran facilitado las facturas o documentos mercantiles falsos que sirvieron para concretar los resultados lesivos para el Fisco, como fue la conducta imputada al Sr. González.

Asimismo, el fallo recurrido sostuvo que solo a partir de la dictación de la Ley 19.738, de 19 de junio de 2001, es decir, posterior a los hechos denunciados, se incorporó expresamente en el inciso final del art 97 № 4 CT la conducta realizada por el Sr. González, lo que corrobora que la conducta imputada al Sr. González no era constitutiva de infracción penal alguna de acuerdo a. art. 97 №4 incisos $1^{\circ}$ y $2^{\circ}$ CT al momento de los hechos (1999), y solo vino a constituir delito a partir de la dictación de dicha ley (2001). Todo esto lo corrobora la historia de dicha ley (que se comenta latamente).

Agrega el fallo de alzada que no es posible extender dichos tipos penales (anteriores a 2001) a otras conductas, por no estar permitida en materia penal la analogía, pues ello es contrario a los principios constitucionales de legalidad y tipicidad.

Bien, la Corte Suprema considera plenamente acertadas las fundamentaciones del fallo recurrido.

Respecto de la cita, efectuada por el recurrente, de sentencias anteriores (precedentes jurisprudenciales) avalando su tesis relativa a la 
eventual comunicabilidad a los demás partícipes de la calidad de contribuyente del principal infractor, la Corte Suprema llama a no olvidar que en el sistema del CdePP rige plenamente el sistema del efecto relativo de las sentencias, que solo tienen fuerza respecto del caso para el que se pronuncian, lo que supone resolver caso a caso, por tratarse de antecedentes fácticos y jurídicos diferentes en cada uno de ellos, y tal como se indica en la propia querella criminal del SII, los hechos derivaron también en la presentación de otra querella criminal, de la contribuyente SACYR S.A. dirigida en contra de dos gerentes de dicha empresa, por los delitos de apropiación indebida y estafa, pues se acreditó que los supuestos materiales adquiridos a TRANSMETAL nunca ingresaron a la SACYR, pero que igualmente los dineros que implicaron esas adquisiciones irreales se pagaron efectivamente a terceros, en una suerte de maquinación de un grupo de personas externas a SACYR, con el objetivo de sustraerle efectivamente esos dineros. Y por otro lado, consta de la misma descripción fáctica que la contribuyente SACYR, una vez determinados los impuestos no pagados producto de la anterior situación, procedió a pagar su deuda a Tesorería General de la República

Finaliza la sentencia de la Corte Suprema, indicando que los hechos acreditados en el proceso no pueden ser enmendados por el tribunal de casación, dado que los jueces del fondo son soberanos en su establecimiento y no se adujo a su respecto ningún quebrantamiento de las leyes reguladoras de la prueba que permita su revisión, por lo que ellos serán considerados para resolver el recurso.

10. CASO "CONTRA LEHMANN WOLFENSON, GASTÓN". CORTE SUPREMA, SENTENCIA DE 3 DE DICIEMBRE DE 2009, AUTOS ROL 8006-08. RECURSO DE CASACIÓN EN EL FONDO, ACOGIDO. MATERIA: FRAUDE ADUANERO, CONTRABANDO, ACCIÓN CIVIL EN PROCESO PENAL

El Sexto Juzgado del Crimen de Santiago dictó sentencia de primera instancia el 5 de marzo de 2007, absolviendo al acusado Sr. Lehmann del cargo de autor del delito de fraude aduanero. El Consejo de Defensa del Estado dedujo recurso de apelación, que finalmente desestimó la Corte de Apelaciones de Santiago, en sentencia de 28 de octubre de 2008. El Fisco interpuso recurso de casación en el fondo.

En su recurso, el Fisco alega que la infracción de la sentencia recurrida consistió en calificar como lícito un hecho que la ley penal califica como delito, absolviendo al acusado. Entre las normas infringidas se encontraría el art. $19 \mathrm{~N}^{\circ} 3 \mathrm{CPR}$, diversas disposiciones CP, CdePP y CC, y los arts. $10 \mathrm{~N}^{\circ} 2$ letra e) de la ley 19.738 y 176, 187 letra f), $184 \mathrm{~N}^{\circ} 1$ y 188 de la Ordenanza de Aduanas.

Argumenta que el art. $10 \mathrm{~N}^{\circ} 2$ letra e) de la ley 19.738 fue erróneamente interpretado puesto que fue dictada con el propósito de combatir la evasión tributaria, refundiendo los delitos de contrabando y fraude bajo la primera denominación (sea el denominado propio como el impropio), pero sin suprimir tal delito, lo que además se desprende del art. 168 de la OA y el art. 24 de la ley 19.738, existiendo identidad material 
entre la conducta típica del antiguo delito de fraude aduanero y el ahora contenido en el contrabando impropio.

La sentencia impugnada, sin fundamento alguno, tampoco hizo aplicación del art 9o transitorio de la ley 19.738, que dispone que los delitos de fraude y contrabando cometidos antes de la vigencia de esa ley se regirían por el actual art 168 de la OA. Esa norma se ocupó, entonces, del tema de la irretroactividad, de modo que no tienen cabida el art $19 \mathrm{~N}^{\circ} 3$ constitucional o el art $18 \mathrm{CP}$.

Finalmente, dado que a consecuencia de la absolución se decidió rechazar la demanda civil, se vulneraron varias disposiciones del CC, que imponen la reparación patrimonial al Fisco.

Por su parte, la Corte Suprema describe en su sentencia los elementos fácticos que constan en el proceso, indicando que el hecho que se tuvo por establecido en la sentencia de primera instancia, consiste en que personal fiscalizador del Servicio Nacional de Aduanas, se constituyó en el almacén particular de la empresa Central Médica S.A., fiscalizando las mercaderías sujetas al régimen suspensivo de derechos ahí almacenadas, constatando que en el lugar no se encontraba el consignatario, ni tampoco la mercadería, sin haber pagado previamente los respectivos impuestos y gravámenes que lo afectaban.

La defensa, por su parte, en su escrito de contestación a la acusación manifestó no haber tenido participación en el injusto, y cuestionó la atipicidad de su actuar, y si bien el acusado admite que extrajo las mercaderías desde el almacén (donde aquellas legalmente debían estar) sin pagar previamente los derechos que se encontraban pendientes, lo hizo porque debió restituir el inmueble donde aquellas se encontraban y porque cayó en quiebra. Sin embargo, ambas circunstancias no fueron acreditadas y por ello la Corte Suprema las desecha.

En cuanto a los aspectos de Derecho, la sentencia recurrida sostuvo que el art. $10 \mathrm{~N}^{\circ} 2$ letra e) de la Ley 19.738, DO de 19 de junio de 2001, derogó el inciso $2^{\circ}$ y $3^{\circ}$ del art. 168 de la OA, quedando limitado de conformidad al art. 168 bis $\mathrm{OA}$, el delito de fraude aduanero a la declaración manifiestamente falsa en cuanto al peso, cantidad o contenido las mercancías de exportación, como también la falsificación de certificaciones o análisis que se exigen para establecer el peso, cantidad o contenido de las mercancías de exportación", de manera que cualquier acción en los términos de perjudicar los intereses fiscales, a la fecha de dictación de la acusación fiscal, no era constitutiva de delito.

La sentencia impugnada concluyó que no obstante encontrarse acreditado en autos el no pago de los derechos correspondientes por parte del acusado en representación de Central Médica S.A., a los cuales se encontraba obligado, por estar sujetas las mercaderías importadas a un régimen suspensivo de almacén particular, no es menos cierto que de conformidad al art. 18 del CP y según la nueva redacción de los arts. 168 y 168 bis de la OA, no es posible concluir que dicha conducta constituya un hecho punible y que en la misma le haya correspondido participación culpable al acusado.

La Corte Suprema enfatiza que la conclusión de haberse despenalizado el contrabando, constituye un error de derecho de la sentencia de alzada, que constituye efectivamente la infracción establecida 
en el art 546 №4 del CdePP, lo que ha sido objeto de pronunciamiento en diversos fallos de esta Corte, en el sentido que pretende la recurrente (cita los autos rol №o 3862-01, 2420-08 y 4999-08.).

Recuerda, asimismo, que la Ordenanza de Aduanas establecía en su art. 168, vigente a la fecha del hecho de autos, define expresamente los delitos de fraude y de contrabando (distinción también presente en el art. 24 de la Ley 19.738). La Ley 19.738 sobre Normas para combatir la evasión tributaria, publicada en DO de 19 de junio de 2001, que modificó la Ordenanza de Aduanas, introdujo en su art 10 letra e) diversos cambios en el art 168. La modificación legal se limitó a refundir en un solo delito los que antes eran los de fraude y contrabando, y bajo esta última denominación, distinguió el contrabando propiamente tal del inciso segundo, con verdaderas figuras de fraude bajo la forma del denominado "contrabando impropio". En efecto, incurre en delito de contrabando el que introduzca mercaderías extranjeras desde un territorio de régimen tributario especial a otro de mayores gravámenes, o al resto del país, en algunas de las formas indicadas en la norma citada, una de las cuales consiste precisamente en ejecutar la acción descrita en el proceso, defraudando la hacienda pública mediante la evasión del pago de los tributos que pudieran corresponderle.

El Tribunal de casación cita un precedente judicial: "Como ya se expresó, antes de la reforma, la norma definía el fraude aduanero como todo acto que elude o frustre las disposiciones aduaneras precitadas con el ánimo de perjudicar los intereses fiscales en cualquiera forma. De ello se evidencia el claro propósito del legislador de mantener la figura del fraude aduanero toda vez que los elementos del tipo corresponden a ella, subsumida bajo el nombre de contrabando, como ya se ha dicho, pero además bajo la forma de delito de resultado y no de peligro como en su redacción anterior. El hecho de eludir restricciones legales imperativas para el ejercicio de un beneficio tributario-aduanero obtenido, de lo cual se deriva la falta absoluta de ingreso en arcas fiscales del mismo, constituye fraude aduanero tanto bajo el imperio de la ley antigua como bajo la nueva, lo que se contrapone con toda idea de derogación del hecho punible objeto de esta causa, como lo ha estimado la sentencia recurrida". (Rol $N^{\circ} 2420$ 08).

La sentencia también se sustenta en la historia fidedigna de la Ley $\mathrm{N}^{\circ}$ 19.738, sobre la base de que el legislador tuvo como propósito explícito el de combatir la evasión tributaria. La historia muestra que las enmiendas de carácter penal y su redacción apuntan en lo esencial, a mejorar técnicamente los tipos penales descritos en el art. $168 \mathrm{OA}$, describiendo con mayor precisión las distintas conductas punibles, que se configuran como modalidades de comisión de un mismo delito, el de contrabando, lo que se refleja tanto en las discusiones parlamentarias como en el Mensaje del Presidente de la República, destacando que la reforma "busca que tenga mayor acogida jurisprudencial [la persecución de fraudes], evitando los defectos actuales. El tipo penal tiene por objeto castigar conductas que se cometen con ocasión de una operación aduanera, pero encaminadas a obtener cualquier beneficio tributario, ya sea en el orden externo o interno, en detrimento del patrimonio del Fisco".

Finalmente, argumenta que el art $9^{\circ}$ transitorio de la Ley № 19.738 
dispone que los delitos de fraude y contrabando cometidos con anterioridad a la fecha de publicación de esa ley, se regirán por el actual art 168 de la $\mathrm{OA}$, en la redacción aprobado por el DFL $\mathrm{N}^{\circ} 2$ del Ministerio de Hacienda de 1997.

En lo que respecta al art $19 \mathrm{~N}^{\circ} 3$ inciso penúltimo constitucional y al art $18 \mathrm{CP}$, la reforma no modificó la entidad de las penas aplicables a estos delitos, de modo que la nueva norma no resulta más favorable, ya que no exime el hecho de toda pena ni le aplica una menos rigurosa.

Por lo anterior, la sentencia acoge el recurso de casación en el fondo, y se hace lugar a todas las solicitudes de la recurrente.

11. CORTE DE APELACIONES DE VALPARAÍSO, SENTENCIA DE 10 DE DICIEMBRE DE 2009, AUTOS ROL 1188-09. CASO "CONTRA

DÍAZ CAROCA, ARTURO”, RECURSO DE NULIDAD, RECHAZADO. MATERIA: FRAUDE AL FISCO, DELITO ADUANERO, PONDERACIÓN DE LA PRUEBA

La primera instancia de esta causa fue ventilada ante el Tribunal de Juicio Oral en lo Penal de Valparaíso. El condenado dedujo recurso de nulidad en contra del juicio y de la sentencia definitiva dictada el 22 de Octubre de 2009, que le impone diversas penas en calidad de autor del delito de fraude al Fisco, ocurrido en Valparaíso el 13 de Agosto de 2008. El recurrente invoca la causal prevista en el art 374 , letra e), del CPP, en relación con los arts. 342, letra c), 297 y 340 del mismo texto legal. El recurso se declaró admisible, realizándose la audiencia el 20 de Noviembre de 2009.

El recurrente sostiene que la causal de nulidad se configura por el hecho de que el análisis, efectuado en la sentencia, de la prueba rendida en el juicio oral para dar por establecida la participación del recurrente como autor del delito de fraude al Fisco, no cumple con los requisitos ni con el estándar de convicción legales, lo que se traduce en que el fallo no cumple a cabalidad con los requisitos exigidos por la normativa respectiva.

La acusación fiscal expresó que los hechos imputados constituían el delito de contrabando aduanero, previsto en los arts. 168, inciso $3^{\circ}$, y 178 № 1 de la OA, del que los acusados serían autores, conforme al art. 15 № $1 \mathrm{CP}$.

Por su parte, el tribunal dio a los hechos, respecto del recurrente Sr. Díaz Caroca, una calificación distinta, considerándolos como delito tipificado en el artículo 239 CP de fraude al Fisco, ilícito por el cual, en definitiva, lo condenó.

El recurrente argumenta que la sentencia impugnada no se ajustaría a las exigencias legales, doctrinales y jurisprudenciales en materia de motivación de las decisiones judiciales, vicios que configurarían la causal de nulidad invocada, en lo particular, no cumple con el estándar y metodología de valoración que prescribe el art. 297 del CPP, en la valoración de la prueba de cargo, en especial la prueba testimonial constituida por las declaraciones de los testigos funcionarios de Aduana, funcionarios policiales de Investigaciones de Chile, presentados en la audiencia de juicio oral, como tampoco respecto de la prueba documental y 
objetos incautados, libro y registro computacional. Agrega que el tribunal a quo solo se hizo cargo parcialmente de la prueba rendida, de manera tal que, de haber analizado cada uno de los medios de prueba en su integridad, no habría llegado al asentamiento de hechos contenido en el fallo recurrido. Asevera que, por otra parte, otorgó pleno valor a la prueba de cargo y, en especial, a las declaraciones de los funcionarios de Aduana, en circunstancias que no permiten superar la presunción de inocencia del acusado, y que, aún más, constituyen una duda razonable acerca de la participación culpable de este. Sostiene que a lo anterior se une la falta de veracidad, solidez y coherencia de las diligencias investigativas llevadas a cabo por la Brigada de Delitos Portuarios de Investigaciones de Chile, lo que habría quedado de manifiesto por lo declarado en el juicio por diverso oficiales policiales.

Argumenta que el delito de fraude al Fisco, por el que se le condena, requiere dolo directo y, según confirma el propio fallo, ninguno de los testigos de cargo antes referidos, señaló ni aportó en parte alguna de sus declaraciones, antecedentes ciertos precisos y contundentes que pudieran hacer ver al sentenciador alguna su participación dolosa. Precisa que lo único que dejan en claro es que el acusado no efectuó materialmente un aforo físico que según ellos debía realizarse, pero no aportan nada acerca de la existencia de alguna concertación criminal entre el recurrente (funcionario de Aduanas) y algún tercero tendiente a permitir dolosamente la salida del container de los recintos portuarios. Agrega que tampoco ello se desprende de la declaración de los otros testigos presentados por el ente acusador, ni menos de los instrumentos y otros objetos incorporados al juicio. Señala que lo único que podría eventualmente estar acreditado, sería un actuar culpable y/o negligente del funcionario, que en ningún caso alcanza para sancionarlo penalmente.

A continuación, cuestiona los razonamientos que llevaron a construir los siete indicios que conducen al tribunal a considerar que el acusado cometió el delito de que se le imputa, explicando por qué era imposible para el recurrente haber participado en los delitos que se le imputan.

Continúa argumentando que las conclusiones del tribunal a partir de la prueba no son exactas para probar lo que este dice probado, que los hechos son efectivamente distintos, como se desprende de un análisis de la totalidad de las pruebas contenidas en el expediente. Concluye que no puede estar más alejada de la prueba rendida lo expuesto por el tribunal en relación a que las presunciones o indicios en su conjunto tendrían la contundencia necesaria para destruir el principio de inocencia del acusado pues, al contrario, esos indicios representan un claro error de apreciación y valoración probatoria, de manejo antojadizo de la prueba indiciaria, lo que conduce a concluir al recurrente que el tribunal a quo ha pronunciado su sentencia apartándose de los preceptos del CPP que consagran el estándar de convicción y el principio de duda razonable, normas que establecen un sistema objetivo y racional de valoración de la prueba.

El recurso, a continuación, denuncia los principios de valoración de la prueba que estima infringidos y que se encuentran establecidos por el art 297 del CPP, en particular, los principios de la lógica (principio de no contradicción, principio de la razón suficiente). Adiciona que también se violó el estándar de valoración exigido por el inciso $2^{\circ}$ del art 297 del CPP, 
al omitir la valorización de la prueba rendida favorable al imputado (en definitiva, de toda la prueba rendida), concordante con la teoría del caso planteada por la defensa.

La Corte, por su parte, inicia fundamentando su rechazo del recurso recordando que el recurso de nulidad ex art. 372 del CPP, es de derecho estricto, por lo que, cuando se funda en la causal prevista en el letra e) de su artículo 374, en relación con lo dispuesto en sus arts. 342 , letra c), y 297, como ocurre en este caso, es necesario determinar si en la sentencia se cometió la infracción a dichos preceptos que denuncia el recurso, sin que sea procedente reabrir por esta vía la apreciación de la prueba rendida en el juicio, atribución privativa de los jueces del fondo. A la luz de estos principios, es posible apreciar que las argumentaciones, reproches y reparos que el recurrente formula en contra de las apreciaciones que formulan los jueces de la causa respecto de la prueba rendida no pueden ser abordados por esta Corte por la vía del recurso de nulidad, pues ello implicaría que este tribunal entrara a replantearse los raciocinios y conclusiones a que llegaron los jueces de la causa a la luz del mérito de las pruebas introducidas al juicio, lo que le está vedado por la ley. En esta parte de su recurso, el recurrente no indica cuál es el principio o norma que los sentenciadores habrían infringido al apreciar la prueba de la causa, sino que disiente de sus raciocinios, los impugna y controvierte. Por estas razones, la Corte advierte que no entrará a hacerse cargo de estas alegaciones del recurso, pues ello implicaría entrar a ponderar el fondo en materia de prueba.

En consecuencia, el fallo se circunscribirá al examen y resolución de los vicios que determinadamente el recurso denuncia en relación con las leyes y principios que los sentenciadores debieron aplicar al proceder al establecimiento de los hechos de la causa.

Respecto de la supuesta infracción de los principios de la lógica a que se refiere el inciso $1^{\circ}$ del art 297 del CPP, la Corte lo desestima por estas razones:

a) El principio de no contradicción, consistente en declaraciones contradictorias de los testigos, que el tribunal además valora como prueba del ilícito. La alegación de este vicio así planteada por la recurrente, no puede ser acogido, por cuanto la infracción al principio lógico de no contradicción, no encuadra en el concepto que da a entender el recurrente. No contradicción significa que un discurso lógico no puede contener afirmaciones o conclusiones contradictorias entre sí, y no que no exista contradicción entre declaraciones de testigos. Además, el recurso no señala cuáles serían determinadamente los pasajes o consideraciones del fallo que se encontrarían en contradicción entre sí, ni cómo este supuesto vicio influye en el establecimiento de los hechos y en la decisión del fallo.

b) El principio de la razón suficiente estaría infringido para el recurrente porque el tribunal daría por establecidos los hechos de la acusación, básicamente en atención a lo declarado por los funcionarios de aduana, no siendo suficiente ni en sí mismas ni en relación a todos los medios de prueba rendidos.

La Corte afirma que el principio lógico de razón suficiente implica que 
las proposiciones de un discurso deben encontrarse formalmente basadas en premisas que le sirvan de fundamento y las justifiquen como consecuencia o efecto de las mismas. La gratuidad en las aseveraciones es la contrapartida de este principio.

En este punto, el recurso no expresa en qué consistiría la falta de razón suficiente que imputa a la sentencia recurrida, ni en qué raciocinio de ella se apreciaría dicho vicio, ni cuál habría debido ser el correcto razonar que el sentenciador debió haber adoptado y que lo habría conducido a conclusiones diferentes de aquellas a que arribó.

c) En relación a una infracción al principio de falta de razón suficiente de otro hecho defendido por el recurrente, se sustenta en razones de mérito en cuanto a hechos que él considera acreditados, en circunstancias que la causal de nulidad esgrimida exigía demostrar la falta de razón suficiente en el razonar de los sentenciadores cuando se refirieron a la presunción o indicio de actuación dolosa en el acusado.

El hecho defendido por el recurrente no está dado por acreditado en la sentencia y no es posible entrar a ponderar si efectivamente se encuentra acreditado por la vía del recurso de nulidad.

d) El recurso da por infringido por el fallo el principio de razón suficiente, en relación a otro hecho defendido por el recurrente. Pero aquí el recurso no explica cuál habría sido el error de lógica en que habrían incurrido los sentenciadores por no haber respetado el principio de razón suficiente, ni señala cuál habría sido un correcto raciocinio que habría conducido a los sentenciadores a asentar una conclusión diferente a la que establecieron.

e) Respecto de los indicios que conducen al tribunal recurrido a estimar la existencia de una actividad delictiva, también el recurso presenta el mismo vicio. Genéricamente, no se aviene con los requisitos formales de interposición de un recurso de nulidad, y, por la otra, su falta de precisión impide a esta Corte entrar a considerar cuáles serían exactamente los vicios invocados, por lo que no resulta admisible.

En cuanto al estándar de valoración de la prueba exigido por el inciso $2^{\circ}$ del art. 297 del CPP, el recurso recrimina a la sentencia impugnada no haber valorado íntegramente la prueba rendida en el proceso, específicamente, de algunos documentos. Sin embargo, ello no es así, ya que aparece considerado en el fundamento $12^{\circ}$ del fallo recurrido. Por ello, también desestima esta alegación.

En relación a la impugnación de no cumplir con el estándar de valoración de la prueba contemplado en el inciso $3^{\circ}$ del art. 297 del CPP, en particular, por no efectuar una fundamentación que permita la reproducción del razonamiento utilizado para alcanzar la conclusión a la que arriba. A su respecto, la fundamentación del recurso resulta ambiguo y carente de la necesaria precisión, pues no indica cuáles serían los raciocinios o conclusiones del considerando $20^{\circ}$ del fallo que adolecerían del vicio que hace valer, sin que, por lo demás, de la lectura de ese considerando aparezca el defecto que se le censura. Por tanto, también desestima estas alegaciones. 
Finalmente, en relación a la influencia que en lo dispositivo del fallo recurrido tendrían los errores en la valoración de la prueba que se reclaman, el recurso formula una declaración genérica, sin determinar concretamente cuál es la consecuencia que para lo dispositivo de la sentencia acarrean cada uno de los vicios o defectos que denuncia, lo que obsta también al acogimiento del mismo.

\section{COMENTARIOS}

1. Una tesis que recurrentemente ha sido planteada por las defensas de los contribuyentes, sostiene que la anulación de un procedimiento sustanciado por funcionario con potestades jurisdiccionales delegadas, y que por ello no es juez tributario, y especialmente si este ha proveído el libelo de reclamación tributaria, no es idóneo para producir la interrupción de los plazos de prescripción de las obligaciones tributarias. Implícita en dicha tesis, se encuentra la idea de que la nulidad del procedimiento de reclamo y su "sentencia" (hay fallos anulatorios que plausiblemente le niegan el carácter de sentencia a esta decisión del funcionario incompetente) quitaría virtualidad a la reclamación en orden a interrumpir dicho plazo y, con ello, debiera entenderse que no ha existido interrupción del plazo de prescripción. Dichos alegatos han sido masivamente rechazados por las Cortes, y con buenas razones (lo que no significa que comparta todas ellas), sobre la base de las claras normas del CT (art. 24) y de los efectos y alcances que dan las Cortes a sus sentencias anulatorias.

El mismo predicamento existe respecto de los reclamos interpuestos ante funcionarios incompetentes (casos $2^{\circ}$ y $3^{\circ}$ ). La excesivamente laxa interpretación de lo que debe entenderse por "interposición o presentación del reclamo" por parte de las Cortes puede conducir (como sucede en estos casos) a que los procesos puedan reproducirse muchas veces y durante muchos años, y todas ellas en beneficio exclusivamente de la Administración Tributaria, esto es, en beneficio de la actividad recaudatoria y en perjuicio de los intereses y derechos de los contribuyentes, y de principios tan caros para el Derecho (para el Estado de Derecho) como la seguridad jurídica o el carácter formal del Derecho (que es lo que le otorga sus sustancia, pues si bien la justicia es un fin del Derecho, el Derecho sin forma termina siendo injusto).

Del mismo modo, las Cortes normalmente han rechazado la alegación de los representantes de las Administraciones Tributarias en orden a considerar extemporánea la excepción de prescripción en segunda instancia.

2. Otra constante, en materia de procedimiento, consiste en que la jurisprudencia normalmente hace recaer todo el peso de la prueba en el contribuyente, bajo la falsa premisa que sostiene que las Administraciones Tributarias no son parte de los procesos tributarios. Si bien esto se funda también en norma legal (en particular, el art. $21 \mathrm{CT}$ ), es especialmente inicuo si se observa que el juez de primera instancia es precisamente quien fiscaliza y exige el cumplimiento de las obligaciones tributarias (de aquellas que estima que existen). El problema se encuentra en que la interpretación y aplicación de la norma del onus probandi es tan extrema y va unida a una facultad de acusación sin prueba tan ilimitada (como 
aparece en el C. $18^{\circ}$ reproducido en el primer caso expuesto), que a mi juicio, es claramente contraria al principio (y derecho constitucional) del debido proceso y al derecho fundamental a la tutela judicial efectiva. Esta situación debiera ser corregida por los nuevos tribunales tributarios de la ley 20.322.

3. El caso $5^{\circ}$ muestra que aún sigue abierto un debate que pervive no obstante la existencia de una gran corriente mayoritaria, relativo al carácter jurisdiccional o administrativo del funcionario público que resuelve el reclamo tributario.

En Chile existe una posición un tanto ideológica respecto del contenido de la función judicial (potestad de resolver conflictos) la que, si bien tiene aspectos razonables, esconde de tras de sí aspectos esenciales de la realidad práctica, de la propia "naturaleza de las cosas". Considerar juez al Director del SII (o que el SIl no constituye parte) ha terminado justificando lo injustificable, y dando carta de legitimidad (otorgándole cualidades que no tiene) a un proceso, en que una de las partes lo resuelve, y a un decisor que carece de imparcialidad e independencia (que desde la racionalidad jurídica no puede ser considerado juez). En dichas circunstancias, no existe tutela de Derecho ni de derechos, ni imperio de Derecho, ni Estado de Derecho. Al evadir este debate, hemos perdido la oportunidad de desarrollar una dogmática de nivel apropiado en el ámbito tributario (en sus aspectos procesal, penal, infraccional, sustantivo, etc.). Es decir, una dogmática que nos ponga a distancia de los abusos del Derecho y que perfile al Derecho haciéndolo más eficiente y garantista, más acorde a valores como el bien común, justicia, seguridad jurídica, tutela de derechos, etc. Sin ella, corremos el riesgo de que los nuevos Tribunales Tributarios de la ley 20.322 no concreten adecuadamente la función que la sociedad espera de ellos.

La sentencia $5^{\text {a }}$ muestra el modo en que las sentencias parecen piezas más de retórica que explicaciones de la realidad (que refleje lo que son las cosas y los hechos), asignándole cualidades que no tiene ni el proceso ni el decisor en cuestión. No obstante constituye esta una opinión mayoritaria, el voto minoritario, con todo el valor que tiene la valentía de alzarlo, muestra otra perspectiva de los hechos, que a mi parecer explica algo mejor el carácter o naturaleza del procedimiento de reclamación tributaria y de su órgano decisor.

Lo dicho hasta aquí no significa que comparta todos los criterios del disidente. La matización se debe a que un procedimiento administrativo también debe compartir los principios de legalidad y debido proceso, del mismo modo que el procedimiento judicial. Fallo de mayoría y voto minoritario parecen no ver ello, aunque llegan a distintas conclusiones. En efecto, si el ministro disidente hubiera tenido presente lo que sostengo, habría llegado a la misma resolución anulatoria pero por razones diferentes: el procedimiento, aunque de naturaleza administrativa, debe encauzarse en principios de legalidad, debido proceso, tutela efectiva de derechos, interdicción de la arbitrariedad, etc., todo lo que no sucedió en el caso sub lite.

4. A su vez, el voto mayoritario (la sentencia) se equivoca al estimar que solo viendo al procedimiento de reclamación tributaria como uno judicial va a poder darse garantías al contribuyente. Ello, como he 
indicado, esconde la realidad: el proceso actualmente vigente no da ninguna garantía, al contrario, es profundamente violatorio de los derechos fundamentales procesales (sin considerar otros derechos, como el de propiedad o de libertad de empresa). Una posición garantista no pasa por considerar que da garantías un procedimiento que no las puede dar, sino precisamente por reconocer esta última circunstancia.

Reitero mi juicio, ya anteriormente entregado: hace falta mucho más que nuevos tribunales (que por cierto es un avance) para modificar este escenario de vulneración de derechos del contribuyente.

5. El caso $6^{\circ}$ plantea una cuestión recurrente, vinculado al alcance del juicio jurisdiccional en el recurso de casación en el fondo. Tal es así, que en definitiva lo que para algunos (los recurrentes) constituye la labor propiamente del Tribunal de Casación, para otros no constituye más que un esfuerzo por constituir una tercera instancia. El problema que se genera es que mientras más legalista y restrictivo el criterio jurisdiccional, menor es la posibilidad de que el recurso sea acogido. Asimismo, mientras más débil haya sido la defensa en el curso del proceso o mientras más veces haya fracasado en el curso al procedimiento de casación (en este caso habían fracasado tanto en primera como segunda instancia), más posibilidad de desestimación del recurso. Por otro lado, la existencia de precedentes judiciales en la materia ayuda -aunque no asegura, debido al principio de efecto relativo de la sentencia, tan defendido en nuestro medio, como se observa en el caso $9^{\circ}-$ a predecir un mayor éxito del recurso (como sucede en el caso $10^{\circ}$ ).

Fuera de lo anterior, en lo tributario esta causa plantea nuevamente el grave problema de la justificación de inversiones unido al onus probandi en el ámbito tributario, que conforme a criterios de la Administración Tributaria (que efectivamente adicionan o complementan la ley, en un exceso de actividad sin cobertura jurídica), y a criterios jurisdiccionales restrictivos de la libertad económica del contribuyente (y de su derecho de propiedad), se aumentan las obligaciones del contribuyente, se le obliga a efectuar una serie de acciones a fin de precaverse de la acusación (injusta o infundada, inclusive) del SII, precisamente porque sobre el contribuyente pesa la carga de la prueba frente a cualquier acusación del Servicio, aunque no sea fundada. Es de esperar que la ciencia del Derecho Tributario chilena sea cada vez más exigente en el análisis que se haga del ejercicio de las potestades de la Administración Tributaria, a fin de entregar elementos de juicio al nuevo juez tributario (ley 20.322).

6. El caso $8^{\circ}$ es de interés porque muestra cómo funciona el Derecho, esto es, cómo no existe una respuesta única frente a los casos concretos. Nótese que el análisis del disidente es razonable: la naturaleza jurídica de un hecho contrario a la ley no se modifica (como parece sostener el fallo de mayoría) por el procedimiento usado (contencioso administrativo o penal), si el camino procesal fuera opcional para el actor. El fallo disidente sostiene que "la decisión del SII de no instar por la investigación de delitos tributarios en sede penal, optando por iniciar un procedimiento de reclamación administrativa, no transforma la naturaleza jurídica del hecho ilícito".

La cuestión se genera, a mi parecer, en que la naturaleza penal de un hecho es teóricamente mucho más difícil de probar (por el canon de 
enjuiciamiento requerido, por las exigencias de prueba y de convicción del tribunal) que su naturaleza infraccional, por lo que no podría a priori considerarse penal un hecho que no sea sometido a procedimiento criminal y declarado como crimen, finalmente, por un juez. Solo de ese modo, en definitiva, se le podrá aplicar el estatuto criminal. Si el actor opta por la otra vía, i.e., la administrativa, no podría exigir la aplicación del estatuto criminal ("un procedimiento infraccional... persigue la sanción de una mera falta", sostiene el fallo de mayoría). Estimo que ese sería el razonamiento ínsito en su fundamento.

7. Los casos 9 y 10 se refieren a causas criminales, delitos fiscales, ambos inciden en problemas de aplicación de la ley en el tiempo. Lo interesante de estas causas es la dualidad de criterios entre la Corte de Apelaciones y la Corte Suprema, y que, a mi juicio, son suficientes para justificar la existencia del recurso de casación en el fondo. Lo que se requeriría, sin embargo, es concederle fuerza al precedente dictado en esta sede, a fin de uniformar criterios jurisprudenciales.

8. En el caso $11^{\circ}$ puede plantearse al menos dos consideraciones. En primer término, sobre la pretensión del letrado de constituir el recurso de nulidad en una tercera instancia (como muchas veces sucede con el recurso de casación), lo que no es jurídicamente posible dada la naturaleza de derecho estricto de este recurso. Nótese lo importante que es conocer los alcances y efectos de dicha categoría, que conduce a que no puede cuestionarse ni aún la valoración de la prueba efectuada por el tribunal de la instancia.

Otro aspecto que puede mencionarse, se vincula con el necesario conocimiento y manejo de categorías de la lógica formal y de la lógica informal que permiten evaluar una sentencia a la luz de la actual norma procesal penal. La incompetencia del letrado en este punto conduce inevitablemente a hacer fracasar su presentación.

\section{BIBLIOGRAFÍA CITADA}

UGALDE, R. y GARCíA, J., "La prescripción en materia tributaria", Legal Publishing Chile, 2009.

* Abogado, Licenciado en Derecho por la Pontificia Universidad Católica de Chile; Magíster en Derecho por la Universidad de Chile; Doctor en Derecho Comparado por la Universidad Complutense de Madrid. Profesor de Derecho Tributario, Derecho Económico y Economía de la Facultad de Ciencias Jurídicas y Sociales de la Universidad de Talca. E-mail:pmasbernat@utalca.cl.

1 En el presente trabajo se usarán las siguientes abreviaturas: art. (artículo); C (considerando); CT (Código Tributario); CPC (Código de Procedimiento Civil); COT (Código Orgánico de Tribunales); CdePP (Código de Procedimiento Penal); CPP (Código Procesal Penal); CP (Código Penal); CPR (Constitución Política); DO (Diario Oficial); SII (Servicio de Impuestos Internos); DL (Decreto-Ley); DFL (Decreto con fuerza de ley); LO (Ley Orgánica); LOSII (Ley Orgánica del Servicio de Impuestos Internos); IA (impuesto adicional); IGC (impuesto global complementario); IR (impuesto a la renta); IRPC (impuesto a la renta de primera categoría); IRSC (impuesto a la renta de segunda categoría); IVA (impuesto al valor agregado); LIR (ley impuesto a la renta); LIVA (ley de impuesto al valor agregado); LOC (Ley Orgánica Constitucional); OA (Ordenanza de Aduanas); TGR (Tesorería General de la República); SNA (Servicio Nacional de Aduanas). 
2 UGALDE, R. y GARcÍA, J., “La prescripción en materia tributaria”, Legal Publishing Chile, 2009, pág. 126. 